\title{
Measuring quality of life in patients with myocardial infarction or stroke: a feasibility study of four questionnaires in The Netherlands
}

\author{
Marie C Visser, Peter J Koudstaal, Ruud A M Erdman, Jaap W Deckers, \\ Jan Passchier, Jan van Gijn, Diederick E Grobbee
}

\begin{abstract}
Objective - To test in patients with a history of myocardial infarction or stroke the feasibility of four quality of life measurements - the Nottingham health profile (NHP), the heart patients psychological questionnaire (HPPQ), the sickness impact profile (SIP), and the hospital anxiety and depression scale (HAD).

Design - Subjects were tested and retested after an interval of 14 days: questionnaires were self assessed.

Subjects - Participants were randomly selected from the Rotterdam stroke data bank (stroke patients; $n=16$, mean (SD) age $66.0(11 \cdot 0)$ years and from the population based Rotterdam study (myocardial infarction; $n=20$, mean (SD) age $72 \cdot 7(7 \cdot 9)$ years, controls; $n=17$, mean (SD) age $72 \cdot 8$ $(7 \cdot 3)$ years.
\end{abstract}

Measurements and main results - Mean (SD) administration times for the NHP, HPPQ, SIP, and HAD were $7.9(3.5), 10.5$ $(4 \cdot 3), 21.0(9 \cdot 8)$, and $5 \cdot 5(2 \cdot 8)$ minutes respectively. On average, the test-retest reliability was good, with Spearman correlations ranging from $0 \cdot 31$ to $0 \cdot 95$. In spite of the limited size of the study, all instruments were able to show differences between the study groups. For instance, median SIP total scores for myocardial infarction and stroke patients were 12.4 (interquartile range $7 \cdot 0-19 \cdot 1$ ) and $11 \cdot 4$ $(5 \cdot 9-15 \cdot 4)$ respectively, compared with $7 \cdot 7$ $(3 \cdot 7-11 \cdot 3)$ in the control group ( $p$ values of 0.04 and 0.14 respectively).

Conclusions - This study suggests that use of the four instruments tested may be feasible and reliable for assessing aspects of quality of life in patients with a history of a myocardial infarction or stroke.

(f Epidemiol Community Health 1995;49:513-517)

Department

R A M Erdman

J W Deckers

and Department

of Neurology,

P J Koudstaal

University Hospital Dijkzigt, Rotterdam

Correspondence to: Dr M C Visser, Department of Neurology, University Hospital Utrecht, Heidelberglaan 100 3584 CX Utrecht,

Accepted for publication March 1995

Measurement of disease outcome is an important issue in medical research, especially in treatment trials. In general, this assessment can be applied at several levels of increasing complexity, as follows: (1) biological process, (2) impairments (of separate functions), (3) disability, (4) handicap (in which social roles are included), and (5) quality of life.$^{12}$ Across the spectrum from disease process to quality of life, the measures become applicable to more than one disease. They usually also become less sensitive and less objective but closer to fulfilment of chosen roles and to well being, and therefore more relevant from the patient's point of view. ${ }^{3}$ Quality of life has rarely been measured in controlled trials of patients with cardiovascular disease, although the importance of this measure is widely recognised. Several instruments for measuring quality of life have been developed, but their applicability to these specific groups of patients has hardly been tested. ${ }^{4-8}$

For our feasibility study we selected multidimensional instruments, for which there is wide experience of use. According to previous recommendations, the criteria used for the selection were concept, origin, format, content, scoring, validity, reliability, and responsiveness. ${ }^{910}$ Two general purpose profiles designed for use in general populations were selected - the Nottingham health profile (NHP) and the sickness impact profile (SIP). ${ }^{11-14}$ Both profiles have been applied in patient studies. ${ }^{15-17}$ We also selected a measure specific to heart disease that had been developed in The Netherlands - the heart patients psychological questionnaire (HPPQ) - because of positive experience reported with this questionnaire in patients with heart disease in The Netherlands. ${ }^{18-19}$ Since anxiety and depression are reported in both categories of patients and may influence their quality of life, ${ }^{20-24}$ the hospital anxiety and depression scale (HAD), derived from clinical practice and with a reported practicality of use, was included as an indicator of the presence of anxiety and or depression. ${ }^{25-26}$

The primary objective of the present study was to test the selected instruments for their feasibility in two groups of patients - one with a history of stroke in the previous five years and the other with a history of myocardial infarction (MI) in the previous five years. We studied assessment time and test-retest reliability. In addition, we examined whether, in spite of the limited size of the study, NHP and SIP as general purpose profiles could distinguish between patient groups and control groups.
Patients and methods

Since May 1990, all patients with a stroke or a transient ischaemic attack admitted to the University Hospital Rotterdam Dijkzigt have been registered in the Rotterdam stroke data bank, which was initiated by one of us (PJK). From the data bank we randomly selected 16 
Table 1 Characteristics of the study groups (mean (SD))

\begin{tabular}{llllll}
\hline & $\begin{array}{c}\text { Post MI } \\
(n=20)\end{array}$ & $\begin{array}{l}\text { Post stroke } \\
(n=16)\end{array}$ & $\begin{array}{l}\text { Controls } \\
(n=17)\end{array}$ & $\begin{array}{l}\text { Post MI v } \\
\text { controls }{ }^{*} p\end{array}$ & $\begin{array}{l}\text { Post stoke v } \\
\text { controls }{ }^{*} p\end{array}$ \\
\hline Age (y) & $72 \cdot 7(7 \cdot 9)$ & $66 \cdot 0(11 \cdot 0)$ & $72 \cdot 8(7 \cdot 3)$ & $0 \cdot 96$ & 0.05 \\
Sex (no of men) & 8 & 10 & 9 & 0.68 & 0.85 \\
Time since event (mth) & $17 \cdot 8(9 \cdot 3)$ & $11 \cdot 1(5 \cdot 1)$ & N/A & & \\
\hline
\end{tabular}

${ }^{*} t$ test; N/A $=$ not applicable.

patients who had had an ischaemic stroke more than six months before. One patient had experienced a transient ischaemic attack and the other 15 had had a brain infarct. The infarct was located in the right hemisphere in seven patients, in the left hemisphere in six patients, and in the posterior fossa in one patient: one patient had experienced multiple infarctions. All patients were functionally independent and none suffered from aphasia.

From the Rotterdam study we selected 20 patients who had been admitted to hospital because of MI between six and 24 months previously. The Rotterdam study is a prospective follow up study which addresses determinants of the progression of chronic disabling disease in the population of 55 years and over in the district of Ommoord in Rotterdam. Altogether 7983 participants $(78 \%$ of those invited) were recruited between 1991 and 1993. The Rotterdam study focuses on causally related determinants of major diseases in the elderly, especially conditions that interfere with the quality of life. There are four primary areas

Table 2 Content of the measurements

Measurement
Sickness impact profile (12 categories)
Sleep and rest
Emotional behaviour
Body care and movement
Household management
Mobility
Social interaction
Ambulation
Alertness behaviour
Communication
Work
Recreation and pastimes
Eating
No of items

Nottingham health profile

Six domains of experience:

Pain

Physical mobility

Sleep

Emotional reactions

Energy

Social isolation

Seven domains of daily life:

Occupation, jobs around the home, social life, personal life, sex, hobbies, vacations

Heart patients psychological questionnaire (four dimensions)

Wellbeing

Feelings of being disabled

Fispleasure

Social Inhibition

Dummy items

$\begin{array}{r}7 \\ 9 \\ 23 \\ 10 \\ 10 \\ 20 \\ 12 \\ 10 \\ 9 \\ 9 \\ 8 \\ 9 \\ \hline 136\end{array}$

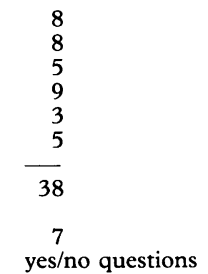

Answers: yes/?/no

Hospital anxiety and depression scale Anxiety.

Depression

Four answers possible per item of research: cardiovascular diseases, neurogeriatric diseases, locomotor diseases, and ophthalmological diseases. After an initial home visit and interview, subjects are examined physically and have several clinical measurements made at a field centre. Some 2.5 years later, changes in health status and clinical measurements are reassessed. ${ }^{27}$

Seventeen controls, matched for age and gender from the MI patients, were selected from the Rotterdam study. Their medical history was negative for MI or stroke. The characteristics of the study groups are shown in table 1 .

The questionnaires included the SIP, NHP, HPPQ, and HAD (table 2). The SIP and NHP are general health profiles - that is, single instruments covering a wide range of dimensions of quality of life with separate scores for each dimension. In both profiles a high score indicates a poor quality of life. The SIP consists of 136 items describing the impact of ill health on behaviour in 12 dimensions. Weighted sum scores are obtained for the overall profile, physical and psychosocial subtotals, and separately for each of 12 categories. The NHP consists of 38 items describing health related behaviour in six dimensions and seven "yes/no" questions concerning domains of daily life (part two). No sum score is derived for NHP. The number of positively answered questions within each dimension is given, as no weighted scores are yet available for the Dutch version of NHP we used. For part two the total number of domains of daily life in which subjects experienced interference is mentioned to indicate differences in the total number of domains in which the subjects feel impaired. Both SIP and NHP have undergone field testing and were shown to be valid measures of health related behaviour in the general population, with high interobserver and intraobserver reliability coefficients. ${ }^{11-14}$

The HPPQ was developed in The Netherlands as a measurement of wellbeing, feeling of being disabled, displeasure, and social inhibition for patients with heart disease. The test consists of 52 items, with a "yes/?/no" response possibility. It has been validated in The Netherlands on a sample of 1649 cardiac patients. ${ }^{18}$ In addition, the quality of life for patients with congestive heart failure has been studied. ${ }^{19}$ Data on the reliability, validity, and norms of this instrument are available for the Dutch population. A higher score in the wellbeing dimension indicates a greater degree of wellbeing, whereas a higher score in feelings of being disabled, displeasure, and social inhibition indicates a worse condition. ${ }^{28}$

The HAD is derived from clinical experience. $^{20}$ Two subscales assess anxiety and 
Table 3 Assessment time instruments, minutes (mean (SD))

\begin{tabular}{|c|c|c|c|c|c|}
\hline & $\begin{array}{l}\text { Post } M I \\
(n=20)\end{array}$ & $\begin{array}{l}\text { Post stroke } \\
(n=16)\end{array}$ & $\begin{array}{l}\text { Controls } \\
(n=17)\end{array}$ & $\begin{array}{l}\text { Post } M I v \\
\text { controls* } p\end{array}$ & $\begin{array}{l}\text { Post stroke } v \\
\text { controls* } p\end{array}$ \\
\hline Nottingham health profile & $8.6(10 \cdot 6)$ & $8 \cdot 6(4 \cdot 0)$ & $6 \cdot 1(7 \cdot 6)$ & $0 \cdot 04$ & 0.06 \\
\hline $\begin{array}{l}\text { Heart patients psychological } \\
\text { questionnaire }\end{array}$ & $10 \cdot 4(11 \cdot 7)$ & $11 \cdot 9(4 \cdot 3)$ & $9 \cdot 0(2 \cdot 9)$ & $0 \cdot 36$ & 0.05 \\
\hline Sickness impact profile & $22 \cdot 1(13 \cdot 1)$ & $23 \cdot 5(7 \cdot 2)$ & $17 \cdot 3(7 \cdot 1)$ & $0 \cdot 27$ & 0.05 \\
\hline $\begin{array}{l}\text { Hospital anxiety and depression } \\
\text { scale }\end{array}$ & $5 \cdot 8(2 \cdot 0)$ & $6 \cdot 5(4 \cdot 2)$ & $5 \cdot 2(3 \cdot 0)$ & $0 \cdot 09$ & $0 \cdot 19$ \\
\hline
\end{tabular}

Table 4 Sickness impact profile (SIP): total score, psychosocial and physical sum scores in the different study groups (median (interquartile range))

\begin{tabular}{|c|c|c|c|c|c|}
\hline & $\begin{array}{l}\text { Post MI } \\
(n=20)\end{array}$ & $\begin{array}{l}\text { Post stroke } \\
(n=16)\end{array}$ & $\begin{array}{l}\text { Controls } \\
(n=17)\end{array}$ & $\begin{array}{l}\text { Post MI v } \\
\text { controls* } p\end{array}$ & $\begin{array}{l}\text { Post stroke } v \\
\text { controls* } p\end{array}$ \\
\hline Sleep and rest & $11.9(0.0-30 \cdot 4)$ & $12 \cdot 1(0 \cdot 0-22 \cdot 0)$ & $0 \cdot 0(0 \cdot 0-12 \cdot 1)$ & $0 \cdot 14$ & $0 \cdot 28$ \\
\hline Emotional behaviour & $3 \cdot 3(0 \cdot 0-19 \cdot 3)$ & $0 \cdot 0(0 \cdot 0-12 \cdot 1)$ & $0.0(0 \cdot 0-0.0)$ & 0.01 & 0.02 \\
\hline Body care and movement & $1 \cdot 2(0 \cdot 0-7 \cdot 3)$ & $3 \cdot 2(0 \cdot 0-8 \cdot 1)$ & $0.0(0.0-3 \cdot 2)$ & 0.48 & $0 \cdot 20$ \\
\hline Household management & $7 \cdot 4(0 \cdot 0-28 \cdot 2)$ & $8 \cdot 1(6 \cdot 1-21 \cdot 3)$ & $0.0(0.0-10 \cdot 4)$ & $0 \cdot 15$ & 0.04 \\
\hline Mobility & $0.0(0.0-23 \cdot 2)$ & $0.0(0 \cdot 0-9 \cdot 2)$ & $0.0(0 \cdot 0-16 \cdot 8)$ & 0.58 & $0 \cdot 82$ \\
\hline Social interaction & $10 \cdot 1(3 \cdot 5-20 \cdot 1)$ & $9 \cdot 6(0 \cdot 0-15 \cdot 4)$ & $4 \cdot 6(0 \cdot 0-12 \cdot 6)$ & 0.09 & 0.38 \\
\hline Ambulation & $11 \cdot 5(7 \cdot 5-28 \cdot 7)$ & $4 \cdot 2(0 \cdot 0-10 \cdot 6)$ & $0 \cdot 0(0 \cdot 0-19 \cdot 9)$ & 0.03 & $0 \cdot 90$ \\
\hline Alertness behaviour & $0 \cdot 0(0 \cdot 0-26 \cdot 5)$ & $0.0(0 \cdot 0-47 \cdot 0)$ & $0.0(0 \cdot 0-10 \cdot 2)$ & 0.31 & $0 \cdot 30$ \\
\hline Communication & $0.0(0.0-0 \cdot 0)$ & $0.0(0.0-9 \cdot 7)$ & $0.0(0.0-9.5)$ & 0.32 & 0.66 \\
\hline Recreation and pastimes & $26.9(18.7-51.5)$ & $17 \cdot 8(0 \cdot 0-41.9)$ & $10 \cdot 2(0 \cdot 0-33 \cdot 0)$ & 0.04 & $0 \cdot 84$ \\
\hline Eating & $0.0(0.0-6 \cdot 1)$ & $0.0(0.0-0.0)$ & $0 \cdot 0(0 \cdot 0-6 \cdot 1)$ & 0.93 & $0 \cdot 08$ \\
\hline SIP total & $12 \cdot 4(7 \cdot 0-19 \cdot 1)$ & $11 \cdot 4(5 \cdot 9-15 \cdot 4)$ & $7 \cdot 7(3 \cdot 7-11 \cdot 3)$ & 0.04 & $0 \cdot 14$ \\
\hline SIP psychosocial & $6 \cdot 8(2 \cdot 3-17 \cdot 2)$ & $8 \cdot 9(1 \cdot 4-20 \cdot 8)$ & $2 \cdot 8(0 \cdot 0-8 \cdot 8)$ & 0.09 & $0 \cdot 10$ \\
\hline SIP physical & $5 \cdot 8(1 \cdot 8-16 \cdot 7)$ & $5 \cdot 1(1 \cdot 6-10 \cdot 3)$ & $3 \cdot 3(0 \cdot 0-8 \cdot 2)$ & $0 \cdot 10$ & $0 \cdot 30$ \\
\hline
\end{tabular}

* Mann-Whitney test.

Table 5 Nottingham heath profile (NHP) scores for different dimensions in the groups (medan (interquartile range))

\begin{tabular}{|c|c|c|c|c|c|}
\hline Dimensions NHP & $\begin{array}{l}\text { Post } M I \\
(n=20)\end{array}$ & $\begin{array}{l}\text { Post stroke } \\
(n=16)\end{array}$ & $\begin{array}{c}\text { Controls } \\
(n=17)\end{array}$ & $\begin{array}{l}\text { Post MI v } \\
\text { controls }^{*} p\end{array}$ & $\begin{array}{l}\text { Post stroke v } \\
\text { controls } p\end{array}$ \\
\hline Energy & $0.0(0.0-1 \cdot 8)$ & $0 \cdot 0(0 \cdot 0-1 \cdot 0)$ & $0.0(0 \cdot 0-0 \cdot 0)$ & 0.01 & 0.01 \\
\hline Pain & $1 \cdot 0(0 \cdot 0-2 \cdot 0)$ & $0.0(0 \cdot 0-1 \cdot 0)$ & $0.0(0.0-0.0)$ & $<0.01$ & $0 \cdot 18$ \\
\hline Emotional reactions & $1 \cdot 0(0 \cdot 0-2 \cdot 0)$ & $0.5(0.0-4.8)$ & $1 \cdot 0(0 \cdot 0-1 \cdot 0)$ & $0 \cdot 14$ & 0.40 \\
\hline Sleep & $1 \cdot 0(0 \cdot 0-3 \cdot 0)$ & $1 \cdot 0(0 \cdot 0-2 \cdot 8)$ & $1 \cdot 0(0 \cdot 0-2 \cdot 0)$ & $0 \cdot 31$ & 0.88 \\
\hline Social isolation & $0.0(0.0-1 \cdot 0)$ & $0.0(0 \cdot 0-2 \cdot 0)$ & $0.0(0.0-0.0)$ & $0 \cdot 23$ & 0.17 \\
\hline Physical mobility & $1 \cdot 0(0 \cdot 0-3 \cdot 0)$ & $1 \cdot 0(0 \cdot 0-2 \cdot 0)$ & $0.0(0.0-1.5)$ & $0 \cdot 23$ & 0.58 \\
\hline Part II & $1 \cdot 0(0 \cdot 3-3 \cdot 0)$ & $1.5(0.0-3.0)$ & $0.0(0.0-0.0)$ & $<0.01$ & 0.01 \\
\hline
\end{tabular}

* Mann-Whitney test.

Table 6 Heart patients psychological questionnaire scores in the different study groups (median (interquartile range))

\begin{tabular}{|c|c|c|c|c|c|}
\hline Dimension & $\begin{array}{l}\text { Post } M I \\
(n=20)\end{array}$ & $\begin{array}{l}\text { Post stroke } \\
(n=16)\end{array}$ & $\begin{array}{l}\text { Controls } \\
(n=17)\end{array}$ & $\begin{array}{l}\text { Post } M I v \\
\text { controls }{ }^{*} p\end{array}$ & $\begin{array}{l}\text { Post stroke v } \\
\text { controls* } p\end{array}$ \\
\hline Wellbeing & $23 \cdot 5(21 \cdot 3-30 \cdot 8)$ & $26.5(18 \cdot 0-30 \cdot 0)$ & $33 \cdot 0(32 \cdot 0-35 \cdot 0)$ & $<0.001$ & $<0.001$ \\
\hline Feelings of being disabled & $29 \cdot 0(26 \cdot 0-35 \cdot 3)$ & $28.5(21.5-33 \cdot 5)$ & $20 \cdot 0(15 \cdot 5-26 \cdot 0)$ & $<0.01$ & 0.02 \\
\hline Displeasure & $16 \cdot 0(11 \cdot 3-18 \cdot 8)$ & $14 \cdot 5(12 \cdot 0-22 \cdot 3)$ & $11 \cdot 0(10 \cdot 0-12 \cdot 0)$ & 0.01 & $<0.01$ \\
\hline Social inhibition & $12 \cdot 0(10 \cdot 3-15 \cdot 8)$ & $13.0(11 \cdot 0-16 \cdot 0)$ & $11 \cdot 0(9 \cdot 0-14 \cdot 0)$ & $0 \cdot 44$ & $0 \cdot 33$ \\
\hline
\end{tabular}

* Mann-Whitney test.

depression and the patient rates each item on a four point scale. Items relating to both emotional and physical disorder are excluded. This is considered to be an advantage since overlap is less likely in this way. ${ }^{29} \mathrm{~A}$ high score indicates anxiety and/or depression. The severity ratings correlate with a structured clinical interview. ${ }^{30}$ It is easily understood and completed by patients, but more work on its reliability and validity is required.

All four questionnaires were self administered. We measured the time needed for completion of the questionnaires. For SIP and HPPQ a score was obtained by means of weights established for the Dutch population. The Mann-Whitney test was used for comparing differences in scores. To establish the test-retest reliability, all instruments were administered by the same person after an interval of 14 days and Spearman correlation coefficients were calculated. The statistical package used was $B M D P^{31}$

\section{Results}

Mean assessment time for the instruments in the different study groups varied between $5 \cdot 2$ minutes for HAD in the control group to 23.5 minutes for SIP in patients with a history of stroke (table 3). For the stoke patients the assessment time was longer for all instruments.

Median values for SIP total score, psychosocial and physical sum scores in the different study groups are presented in table 4 , with corresponding $p$ values. In tables 5, 6, and 7 the results are presented for different dimensions of NHP, HPPQ, and HAD. Most instruments were able to detect differences between the study groups. Statistically significant differences were found for SIP (total score) in the comparison between MI patients and controls (table 4). For separate dimensions of SIP, statistically significant differences were found for emotional behaviour, for both post stroke patients and post MI patients in comparison with controls; for household management in 
Table 7 Hospital anxiety and distress (HAD) scores in the different study groups (median (interquartile range))

\begin{tabular}{llllll}
\hline HAD dimension & $\begin{array}{l}\text { Post } M I \\
(n=20)\end{array}$ & $\begin{array}{l}\text { Post stroke } \\
(n=16)\end{array}$ & $\begin{array}{l}\text { Controls } \\
(n=17)\end{array}$ & $\begin{array}{l}\text { Post MI v } \\
\text { controls* } p\end{array}$ & $\begin{array}{l}\text { Post stroke } v \\
\text { controls* } p\end{array}$ \\
\hline Anxiety & $5 \cdot 0(2 \cdot 0-7 \cdot 5)$ & $7 \cdot 0(3 \cdot 0-10 \cdot 3)$ & $1.5(0 \cdot 0-3 \cdot 0)$ & 0.03 & $<0 \cdot 001$ \\
Depression & $3.0(1 \cdot 0-8 \cdot 0)$ & $8 \cdot 0(2 \cdot 0-10 \cdot 8)$ & $1 \cdot 0(0 \cdot 0-2 \cdot 8)$ & 0.06 & $<0 \cdot 001$ \\
\hline
\end{tabular}

* Mann-Whitney test.

Table 8 Test-retest reliability $(n=42)$

\begin{tabular}{ll}
\hline Instrument & $\begin{array}{l}\text { Spearman } \\
\text { correlation } \\
\text { coefficient }\end{array}$ \\
\hline Sickness impact profile & \\
Psychosocial sum score & $0 \cdot 82$ \\
Physical sum score & $0 \cdot 80$ \\
Total sum score & $0 \cdot 86$ \\
Nottingham health profile & \\
Pain & $0 \cdot 65$ \\
Physical mobility & $0 \cdot 68$ \\
Sleep & $0 \cdot 70$ \\
Emotional reactions & $0 \cdot 80$ \\
Energy & $0 \cdot 86$ \\
Social isolation & $0 \cdot 86$ \\
Part II & $0 \cdot 88$ \\
& \\
Heart patients psychological questionnaire & $0 \cdot 70$ \\
Wellbeing & $0 \cdot 95$ \\
Feelings of being disabled & $0 \cdot 72$ \\
Displeasure & $0 \cdot 67$ \\
Social inhibition & \\
Hospital anxiety and depression scale & $0 \cdot 89$ \\
Anxiety & $0 \cdot 87$ \\
Depression &
\end{tabular}

* All $\mathrm{p}$ values $<0 \cdot 01$.

the comparison between post stroke patients and controls; and for mobility and recreation and pastimes between the post MI patients and controls.

For NHP there were statistically significant differences between both $\mathrm{MI}$ and stroke patients in the comparison with controls in the energy dimension and in part II, and in the pain dimension in the comparison between $\mathrm{MI}$ patients and controls (table 5). For the HPPQ differences in scores were statistically significant in both comparisons in all dimensions except for the social inhibition dimension (table 6 ). The anxiety scores of HAD were significantly different in both comparisons, and the depression score was significantly different between stroke patients and controls (table 7).

Test-retest reliability, calculated with Spearman correlation coefficients, is shown in table 8 . Forty two subjects $(79 \cdot 2 \%)$ agreed to participate in this part of the study. Correlation ranged from $0.31(p=0.05)$ in the SIP sleep dimension to 0.95 for HPPQ in the feelings of being disabled dimension $(\mathrm{p}<0 \cdot 01)$.

\section{Discussion}

This preliminary study indicates that measures of quality of life can be applied within a reasonable time to patients who have had MI or stroke and that these may distinguish even small numbers of patients from controls. Quality of life is an important aspect of health outcome, along with duration of life, and it is of interest as a determinant of outcome as well. ${ }^{32}$ Inclusion of quality of life variables as measures of treatment effects is a valid and necessary addition to the more traditional outcomes considered in medical care, such as survival or the occurrence of specific events. ${ }^{33}$ When the choice is made to include the assessment of quality of life in a study of intervention or prognosis, one or several of the available instruments have to be selected, depending on a review of the literature and specific characteristics of the study. In general, the use of an existing instrument is preferable to designing a new questionnaire because several characteristics such as reliability and validity of existing instruments may be known, although of course for a specific study the addition of extra items can be necessary.

After careful selection, the next step is to test the feasibility and reliability of the selected instruments for the study population. The present study was designed to assess whether some of the instruments used would turn out to be less suitable than others and should be excluded from a planned main study with a larger number of participants. Use of all instruments was feasible in the study groups as judged from an acceptable administration time and from the subjects' reactions. Since the time elapsed since MI or stroke was at least six months, we expected the condition of the patients to remain relatively stable and the correlations between assessments with an interval of 14 days to be high. Test-retest reliability was satisfactory. In spite of the relatively limited number of patients included, the instruments were able to detect differences between the study groups, some of them statistically significant. These results seem promising with regard to the sensitivity of the instruments. That the average age of the stroke patients was six years lower than that of controls may have contributed to the relatively low scores on SIP, but did not prevent the two HAD scores from being significantly higher than in controls.

The implications of some of the findings in the present study groups can be fully addressed only when based on a larger number of subjects. Given the performance of the instruments in the present study, however, we believe that they deserve to be considered by other investigators in similar research.

We thank patients registered in the Rotterdam stroke data bank, participants of the Rotterdam study, and the researchers and research assistants of both studies. We wish to thank Mrs Irma P A M Huijbrechts for her help in the organisation of the study. This study was supported by The Netherlands Heart Foundation.

1 World Health Organisation. International classification of impairments, disabilities and handicaps. Geneva, World Health Organization. 1980.

2 Van Gijn J. Measurement of outcome in stroke prevent trials. Cerebrovascular Disease 1992;2(suppl 1):23-34.

3 De Haan R, Horn J, Limburg M, van der Meulen J, Bossuy P. A comparison of five stroke scales with measures of disability, handicap and quality of life. Stroke 1993;24: $1178-81$.

4 Johansson BB, Jadbäck G, Norrving B, Widner H, Wiklund I. Evaluation of long-term functional status in first-ever 
stroke patients in a defined population. Scand $\mathcal{f}$ Rehabil Med 1992;26(suppl):105-14.

5 Permanyer-Miralda G, Alonso J, Antó JM., AlijardeGuimerá $M$, Soler-Soler J. Comparison of perceived health status in stable patients with coronary artery disease. F Clin Epidemiol 1991;44:779-86.

6 Levin L-A, Jönsson B. Cost-effectiveness of thrombolysis-a randomized study of intravenous rt-PA in suspected myocardial infarction. Eur Heart 7 1992;13:2-8.

7 Granger CV, Cotter AC, Hanilton BB, Fiedler RC. Functional assessment scales: a study of persons after stroke. Arch Phys Med Rehabil 1993;74:133-8.

8 Visser MC, Fletcher AE, Parr G, Simpson A, Bulpitt CJ A comparison of three quality of life instruments in subjects with angina pectoris: the sickness impact profile, the Nottingham health profile and the quality of wellbeing scale. tingham health profile and the quali
7 Clin Epidemiol 1994;47:157-63.

9 Fletcher AE, Dickinson EJ, Philip I. Review: Audit measures: quality of life instruments for everyday use with ures: quality of life instruments for everyda

10 Haan de R, Aaronson N, Limburg M, Langton Hewer R Crevel van $H$. Measuring quality of life in stroke. Strok 1993;24:320-7.

11 Hunt SM, McKenna SP, McEwen J, Backett EM, Williams J, Papp E. A quantitative approach to perceived health status: a validation study. $\mathcal{f}$ Epidemiol Community Health 1980;34:281-6.

12 Hunt SM, McEwan J, McKenna SP. Measuring Health Status, a new tool for clinicians and epidemiologists, $\mathcal{F} R$ Coll Gen Pract 1985;35:185-8.

13 Bergner M, Bobbit RA, Kressel S, Pollard WE, Gilson BS, Morris JR. The sickness impact profile: conceptual formulation and methodology for the development of a health status measure. Int f Health Serv 1976;6:393-415.

14 Bergner M, Bobbitt RA, Carter WB, Gilson BS. The sickness impact profile: development and final version of a health impact profile: development and final version
status measure. Med Care 1981;19:787-805.

15 Bergner L, Bergner M, Hallstrom AP, Eisenberg M, Cobb LA. Health status of survivors of out-of-hospital cardiac arrest six months later. Am $\mathcal{F}$ Public Health 1984;74:50810.

16 Bergner L, Hallstrom AP, Bergner $M$ et al. Health status of survivors of cardiac arrest and myocardial infarction. $A m$ f Public Health 1985;75:1321-3.

17 Caine N, Harrison SCW, Sharples LD, Wallwork J. Pro- spective study of quality of life before and after coronary artery bypass grafting. BMF 1991;302:511-16.

18 Bonsel GJ, Erdman RAM, Mast RC van der, Balk AHMM Maas van der PJ. Psychosociale aspecten van harttransplantatie. Ned Tijdschr Geneeskd 1990;5:227-31.

19 Erdman RAM, Hugenholtz PS, Knippenberg FCE, Laird Meeter K. Quality of life assessment in congestive heart failure: a psychologists and a cardiologists point of view. Netherlands Fournal of Cardiology 1990;3:14-22.

20 Robinson RG, Price TR. Post-stroke depressive disorders: A follow-up study of 103 patients. Stroke 1982;13:635-41.

22 Wade DT, Legh-Smith J, Hewer RA Depressed mood after stroke: a community study of its frequency. Br $\mathcal{F}$ Psychol 1987;151:200-5.

23 Croog SH, Levine S. Life after a heart attack. Social and psychological factors eight years later. New York: Human

24 Wiklund I, Herlitz J, Hjalmarson A. Quality of life five years after myocardial infarction. Eur Heart $\mathcal{f}$ 1989;10:464-72. 25 Zigmond AS, Snaith RP. The hospital anxiety and depression scale. Acta Psychiatr Scand 1983;67:361-70.

26 Bowling A. Measuring health: a review of quality of life measurement scales. Milton Keynes, Philadelphia: Open University Press, 1991

27 Hofman A, Grobbee DE, Jong de PTVM, Ouweland van den FA. Determinants of disease and disability in the elderly: the Rotterdam elderly study. Eur f Epidemiol 1991; 7:403-22.

28 Erdman RAM, Duivenvoorde HJ, Verhage F, Kazemier M, Hugenholtz PG, Predictability of beneficial effects in cardiac rehabilitation: a randomized clinical trial of psycho-social variables. $\mathcal{f}$ Cardiopulmonary Rehabilitation psycho-social varia

29 Fallowfield L. The quality of life: the missing measurement in health care. London: Souvenir Press, 1991.

30 Lewis G, Wessely S. Comparison of the general health questionnaire and the hospital anxiety and depression scale. Br F Psychol 1990;157:860-4.

31 BMDP Statistical software. Los Angeles: BMPD, 1990.

32 Miettinen OS. Quality of life from the epidemiologic perspective. F Chron Dis 1987;6:641-3.

33 Wenger NK: The concept of quality of life: An appropriate consideration in clinical decision making affecting patients with cardiovascular disease. Quality of Life and Cardiovascular Care 1984;1:8-14. 